\title{
Static Stress Analysis of Connecting Rod Using Finite Element Approach
}

\author{
AbhinavGautam $^{1}, \mathrm{~K}$ Priya Ajit ${ }^{2}$ \\ ${ }^{1}$ M.TECH Student, Department of Maintenance Engineering and Tribology, ISM, Dhanbad \\ ${ }^{2}$ Assistant professor, Department of Mining Machinery Engineering, ISM, Dhanbad
}

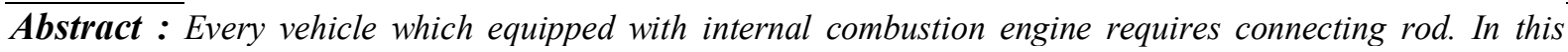
paper a static stress analysis of connecting rod made up of SS 304 used in Cummins NTA 885 BC engine is conducted, using finite element method. After measuring the dimension of connecting rod, model is developed in CATIA V5 software and imported to ANSYS WORKBENCH 14.0 software. Static analysis is done by fixing the smaller end and load is applied at bigger end of connecting rod. Stress developed at four different sections is used for analysis. Maximum stress point and section prone to failure is finding out by this analysis. Graph between stress and load is plotted at section prone to failure and result of stress analysis is shown with the help of image.
\end{abstract}

Keywords: Connecting Rod, Stress Analysis, FEA, ANSYS 14.0

\section{Introduction}

Connecting rod is the important part of an automotive engine. It connects the piston and the crankshaft, transmitting the piston thrust to the crankshaft so that the reciprocating motion of piston converted in to rotary motion by crankshaft. Connecting rod undergoes high cyclic load of order $10^{8}$ to $10^{9}$, that's why it undergoes high amount of compressive loading due to combustion as well as tensile loading due to inertia. Due to these reasons stress analysis become an important factor for selection of material, production process and fatigue parameter.

An extensive literature review was undertaken for the work. Mohammed et al [1] describe the cause of failure of connecting rod by finite element analysis with help of MSC Patran software and also performed the metallographic study of buckled connected rod. The result shows due to some casting defects porosity, crack initiated and propagated on the fractured surface. Pathade et al [2] in his study shows stress analysis of connecting rod at different sections. First connecting rod model is developed in pro/E wildfire 4.0 and FEM analysis is carried out in ANSYS Workbench 11.0 software. Stresses calculated theoretically as well as numerically at different sections by application of three loads. By analysis it is found that stresses induced at smaller end is greater than the bigger end. Failure analysis of connecting rod made up of different material like carbon steel, mild steel, brass and aluminum are represented in the study of Noor et al [3]. First result has found out experimentally and verified numerically by FEM. Geometric parameters of big end of connecting rod is analyzed in the study of Chikalthankar et al [4]. Analysis of connecting rod of light commercial vehicle of Tata motors analytically and by finite element method is carried out in the study of Doshi and Ingole [5]. Connecting rod is designed by machine design approach and compared with the actual production drawing. They also used ProlE wildfire 4.0 for modeling the connecting rod and ANSYS 11 for static analysis at different load. Dynamic analysis of the connecting rod is done by Ram Bansal [6]. In his work model of connecting rod of single cylinder four stroke diesel is modeled in CATIA V5R18 software by measuring the dimensions of the rod and analysis is done on ANSYS. Boundary conditions are measured by dynamic simulation.

Based on the above literature review and study. Stress analysis of connecting rod of Cummins NTA $885 \mathrm{BC}$ engine is presented in this paper. This paper is organized in four sections. Second section is problem formulation, which deals with the moleding of connecting rod in CATIA by measuring the dimensions, engine specifications and load applications. FEM analysis of connecting rod on is done in third section with help of ANSYS WORKBENCH 14.0 and result is analyzed. The work is concluded in fourth section.

\section{Problem Formulation}

For stress analysis two most critical area is considered bigger end and smaller end of connecting rod. Four different sections are consider of stress calculation as shown in fig-1. Load is applied at bigger end and smaller end kept fixed. Three different load which are obtained with the help of engine specifications are used for analysis purpose. First model of connecting rod is created in CATIA V5R18 software. 


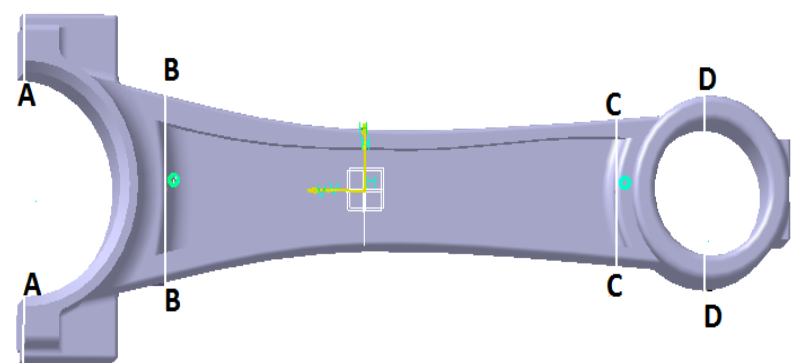

Fig. 1. Different sections of connecting rod

Dimensions are obtained by measuring the dimension of connecting rod by using vernier caliper, micro meter and ruler. Specification of the engine to which connecting rod belong is listed in Table1.

Table no.1.Engine and Connecting Rod Specification

\begin{tabular}{|l|l|}
\hline Engine type & 4 stroke, 6 cylinder \\
\hline Power & $290 \mathrm{HP} @ 1760 \mathrm{rpm}, 300 \mathrm{HP} @ 2100 \mathrm{rpm}$ \\
\hline Stroke, bore & 140 X $152 \mathrm{~mm}$ \\
\hline Mass of connecting rod with cap & $4.39 \mathrm{~kg}$ \\
\hline Mass if connecting rod without cap & $3.32 \mathrm{~kg}$ \\
\hline Swept volume & $885 \mathrm{in}^{3}$ or $14 \mathrm{~L}$. \\
\hline
\end{tabular}

By using engine specification data maximum and minimum normal force acting on the connecting rod is obtained by using torque and power relation $\mathrm{P}=(\mathrm{T} . \omega)$. These results are shown in Table 2 .

Table no 2 Power Developed at Different RPM.

\begin{tabular}{|l|l|l|}
\hline Power (in HP) & Revolution (rpm) & Load developed(kN) \\
\hline 290 & 1760 & 15.39 \\
\hline 300 & 2100 & 13.26 \\
\hline
\end{tabular}

For 300 HP@2100 rpm 13.26 KN force is obtained, for 290 HP@2100 rpm 15.39 KN force is obtained. Third force is the mean of these two forces is $14.325 \mathrm{KN}$. All these three forces are used for the static stress analysis.

\section{FEM Analysis of Connecting Rod Using ANSYS Workbench 14.0}

FEM analysis of a connecting rod is done in ANSYS workbench 14.0 software. First connecting rod model is imported to the ANSYS by converting the Catia file into .Igs extension file format. After successful import of model material property is defined. As this connecting rod is made up of SS 304. The property which is used and necessary for analysis is given in Table 3.

Table no 3. Material property of connecting rod.

\begin{tabular}{|l|l|}
\hline Density & $8.03 \times 10^{3} \mathrm{~kg} / \mathrm{m}^{3}$ \\
\hline Yield tensile strength & $215 \mathrm{MPa}$ \\
\hline Ultimate tensile strength & $505 \mathrm{MPa}$ \\
\hline Compressive strength & $210 \mathrm{MPa}$ \\
\hline Poisson's ratio & 0.29 \\
\hline Young's modulus & $193 \mathrm{GPa}$ \\
\hline
\end{tabular}

After defining the material property meshing is done. Mesh generation is an important phenomena, if mess generation is finethan stress analysis will be accurate and effective. Finite element mesh is generated using parabolic tetrahedral element, taking element size to $5 \mathrm{~mm}$ and minimum edge length as $5.1177 \mathrm{e}-005 \mathrm{~m}$, with 55084 nodes and 31815 elements for full model geometry and 36489 nodes and 20705 elements for geometry without cap. The model without cap is used for the stress analysis. Messed geometry is shown in figure 2 . 

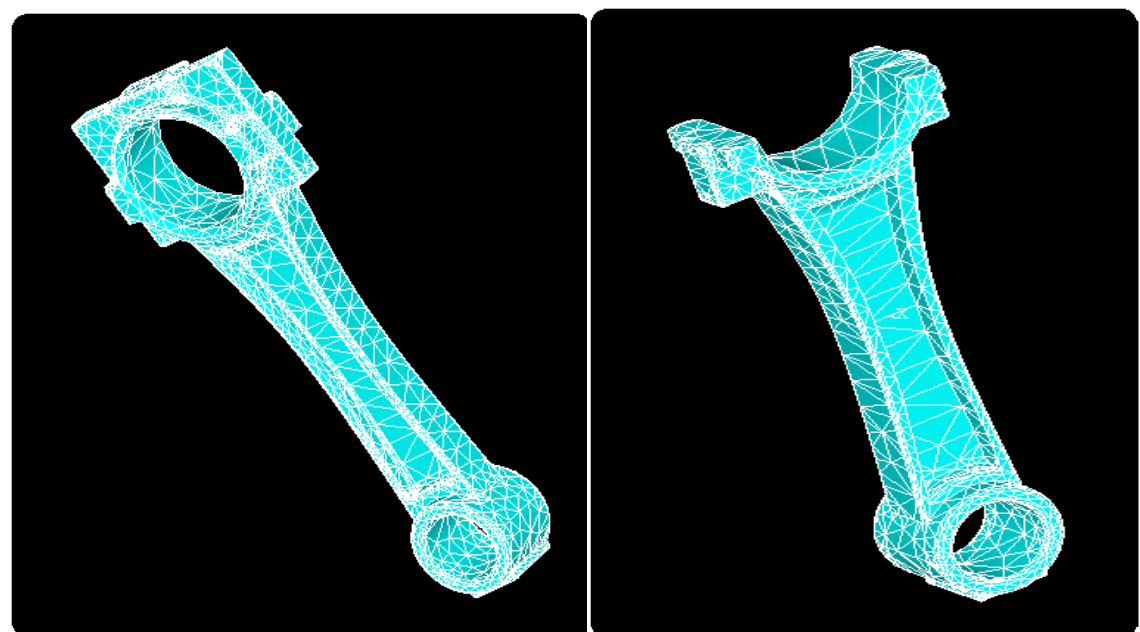

Fig.2.Messed Image of Connecting Rod In Mechanical APDL

For static analysis keeping the small end fixed and apply the load at bigger end. Three different load of amount $15.39 \mathrm{kN}, 14.325 \mathrm{kN}$ and $13.26 \mathrm{kN}$ applied on the bigger end one by one on $180^{\circ}$ of the surface and stress is calculated on four section of the connecting rod by using a probe tool. Several point is selected on each section for obtaining stresses. The amount of stress is developed at the different point of the specific section which is visible in the image. Maximum stresses induced at different section by application of these three different loads are tabulated in table 4. The images of stress analysis at sections are given in figure 3 to 5 .

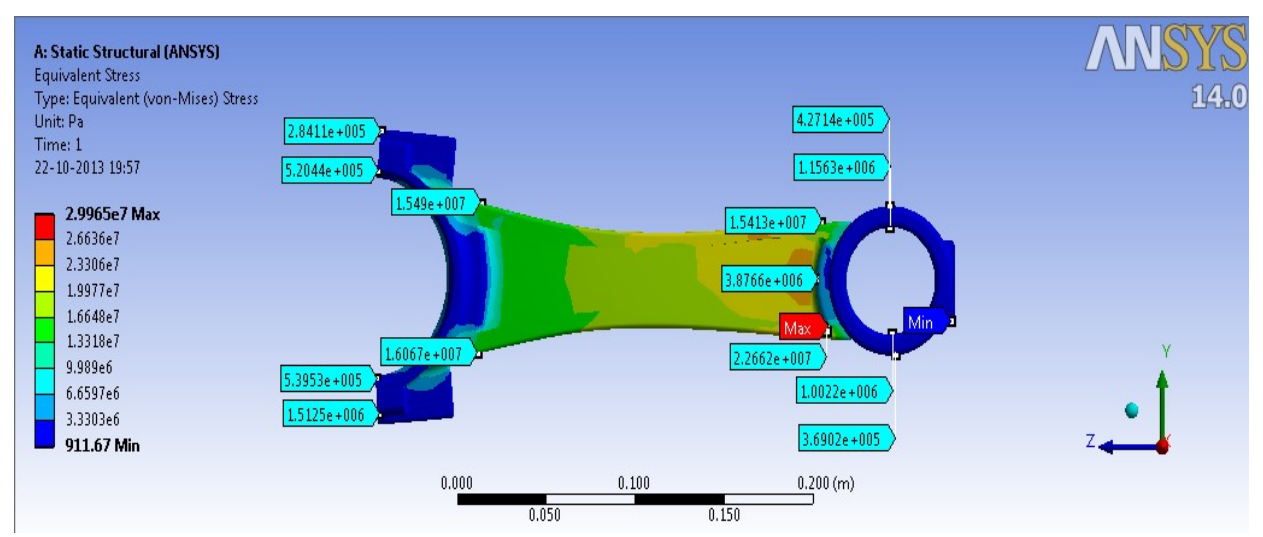

Fig 3.Stress Analysis by Application of 13.26 kN

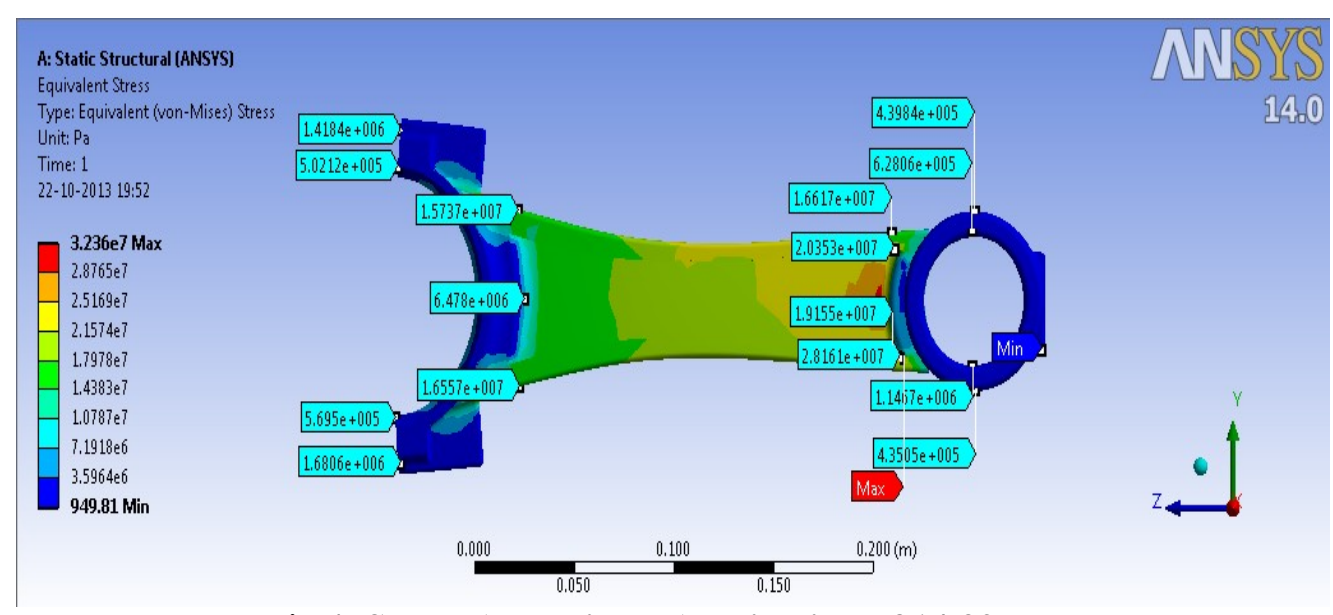

Fig 4. Stress Analysis by Application of 14.325 kN 


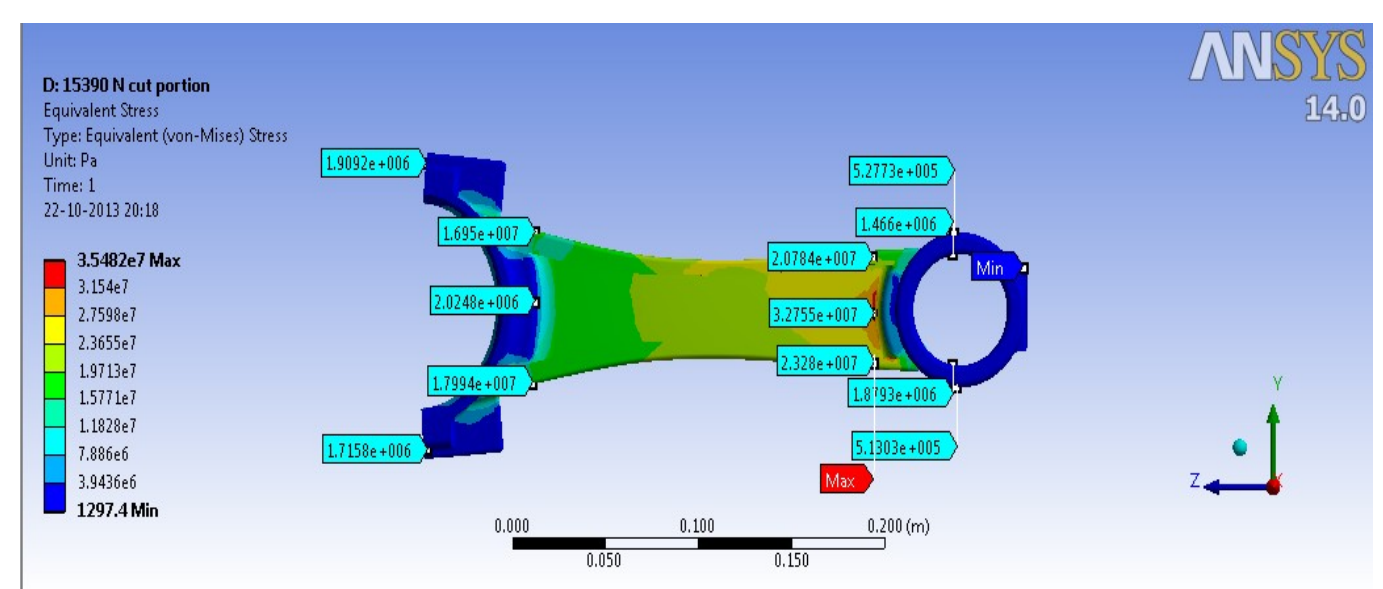

Fig 5. Stress Analysis by Application of $15 \mathrm{kN}$

Table 4. Stress at Different Sections Cross-Ponding To Load

\begin{tabular}{|l|l|l|l|l|}
\hline \multirow{2}{*}{$\begin{array}{l}\text { Load ad } \text { (in }) \\
\end{array}$} & \multicolumn{4}{|l|}{ applied } \\
\cline { 2 - 5 } & A-A & B-B & C-C & D-D \\
\hline 13.26 & 1.51 & 16.06 & 22.66 & 1.15 \\
\hline 14.325 & 1.68 & 16.55 & 28.16 & 1.14 \\
\hline 15.39 & 1.90 & 17.99 & 32.75 & 1.81 \\
\hline
\end{tabular}

The stress distribution at section B-B and C-C is much more than at section A-A and section D-D. loadvs stress graph is plotted for both the section B-B and C-C is shown in figure 6 and 7

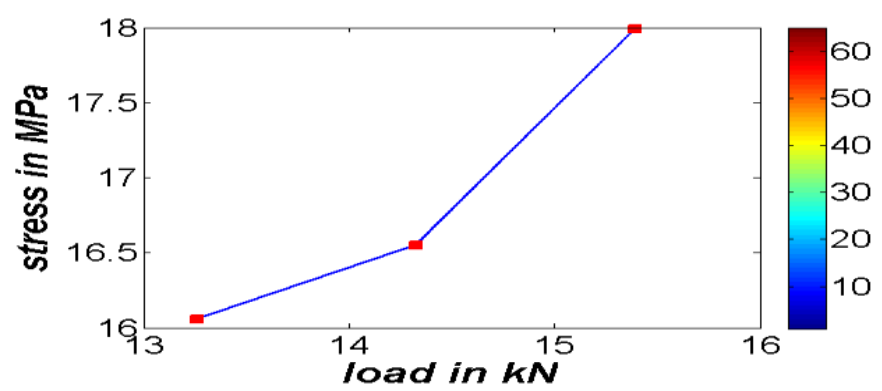

Fig.6. Load Vs Stress Graph at Section B-B

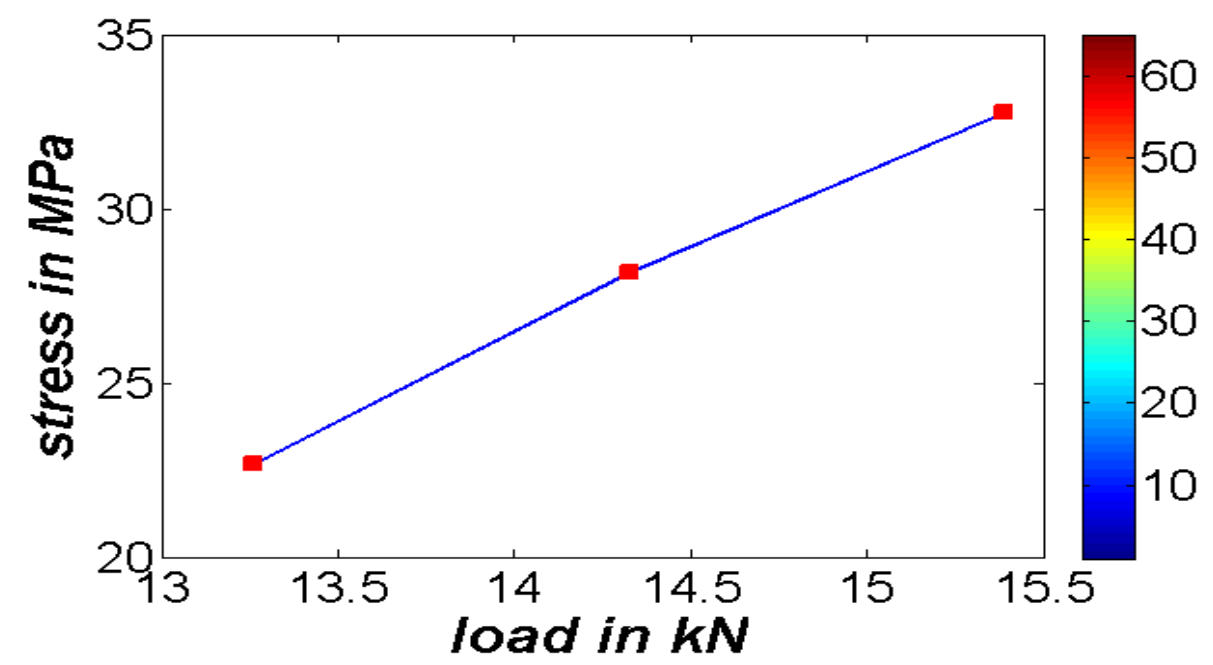

Fig .7.LoadVs Stress Graph at Section C-C 


\section{Conclusion}

It is observed that the area close to root of the smaller end is very prone to failure, may be due to higher crushing load due to gudgeon pin assembly. As the stress value is maximum in this area and stresses are repetitive in nature so chances of fatigue failure are always higher close to this region

\section{References}

[1] Mohammed et al. 'Failure Analysis of a Fractured Connecting Rod'. Journal of Asian scientific research, 2012, vol. 2 issue 11, pp737-741.

[2] Pathade et al. 'Stress Analysis of I.C Engine Connecting Rod' international journal of engineering and innovative technology (IJEIT), march 2012, Vol. 1,issue 3, pp12-15.

[3] Noor et al. 'Analysis of connecting rod based on finite element approach' Malaysian Technical Universities Conference on Engineering and Technology, March 2008, pp95-98.

[4] Chikalthankar et al.'FEA analysis of geometric parameters of connecting rod big end' international journal of engineering science and technology(IJEST), April 2012 Vol. 4,issue 4, pp1560-67.

[5] Doshi and Ingole 'Analysis of Connecting Rod Using Analytical and Finite Element' International Journal of Modern Engineering Research (IJMER), Jan-Feb. 2013, Vol.3, Issue.1, pp-65-68

[6] Ram Bansal 'Dynamic Simulation of a Connecting Rod Made of Aluminum Alloy Using Finite Element Analysis Approach' Method' IOSR Journal of Mechanical and Civil Engineering (IOSR-JMCE), Jan. - Feb. 2013 Vol 5, Issue 2, pp01-05. 